\title{
Global evaluation of erosion rates in relation to tectonics
}

Hagar Hecht ${ }^{1 *}$ and Takashi Oguchi, ${ }^{1,2}$

\begin{abstract}
Understanding the mechanisms and controlling factors of erosion rates is essential in order to sufficiently comprehend bigger processes such as landscape evolution. For decades, scientists have been researching erosion rates where one of the main objectives was to find the controlling factors. A variety of parameters have been suggested ranging from climate-related, basin morphometry and the tectonic setting of an area. This study focuses on the latter. We use previously published erosion rate data obtained mainly using ${ }^{10} \mathrm{Be}$ and sediment yield and sediment yield data published by the United States Geological Survey. We correlate these data to tectonic-related factors, i.e., distance to tectonic plate boundary, peak ground acceleration $(P G A)$, and fault distribution. We also examine the relationship between erosion rate and mean basin slope and find significant correlations of erosion rates with distance to tectonic plate boundary, PGA, and slope. The data are binned into high, medium, and low values of each of these parameters and grouped in all combinations. We find that groups with a combination of high $P G A(>0.2 .86 \mathrm{~g})$ and long distance $(>1118.69 \mathrm{~km})$ or low $P G A(<0.68 \mathrm{~g})$ and short distance $(<94.34 \mathrm{~km})$ are almost inexistent suggesting a strong coupling between $P G A$ and distance to tectonic plate boundary. Groups with low erosion rates include long distance and/or low PGA, and groups with high erosion rates include neither of these. These observations indicate that tectonics plays a major role in determining erosion rates, which is partly ascribable to steeper slopes produced by active crustal movements. However, our results show relatively unclear correlation of slope with erosion rates, pointing to problems with using mean basin-wide slope as a slope indicator because it does not represent the complex slope distribution within a basin.
\end{abstract}

Keywords: Erosion rate, Sediment yield, Basin morphometry, Tectonic plates, Peak ground acceleration, Slope, Geographic information system

\section{Introduction}

Understanding the mechanisms and controlling factors of erosion rates is of great importance as they are related to bigger processes such as tectonic plate movements and climate change. Primarily, erosion is part of the sediment cycling processes. The material eroded on earth surfaces is transported over time into the oceans, subducted into the mantle, and then returns to the surface through volcanism and tectonic uplift. In this way, estimates of erosion rates are a vital component of both sediment and geochemical mass balance studies. The geochemical mass balance includes the carbon cycle as the erosion of silicates and carbonate minerals serves as a transformer of carbon dioxide between the atmosphere and lithosphere. For this reason,

\footnotetext{
* Correspondence: hhecht@csis.u-tokyo.ac.jp

'Department of Natural Environmental Studies, The University of Tokyo, 5-1-5 Kashiwanoha, Kashiwa City, Chiba 277-8563, Japan

Full list of author information is available at the end of the article
}

understanding the controlling factors of erosion rates will not only help understand landscape evolution but also climate change (Kump et al. 2000).

Much work has been done and a lot of energy has been invested in understanding erosion rates. Most studies have concentrated on investigating controlling factors on a local scale and have come to a variety of conclusions regarding what most affects erosion rates ranging from precipitation (e.g., Galy and France-Lanord 2001; Griffiths 1979; Griffiths 1981) to mass wasting events (Hovius et al. 1997) and lithology (Matsushi et al. 2006). In addition, global data have been compiled with the intention of identifying the controlling factors of erosion rates. Ahnert (1970) found that erosion rates are dependent on basin relief, and Milliman and Syvitski (1992) found a link between erosion rates and basin area. Portenga and Bierman (2011) found that while basin-wide erosion rates are correlated best to basin slope, erosion rates for 
outcrops are most strongly correlated to mean annual precipitation.

Another dominant controlling factor that shows up in many studies, both global and local, is the rate of tectonic uplift. A study in South Africa concluded that the reason for the very slow erosion rates despite alpine topography is tectonic stability (Scharf et al. 2013). A similar example is Sri Lanka where even though there are high temperatures, precipitation, and relief, erosion rates are relatively low because the country is situated in a cratonic area that lacks tectonic activity (Von Blanckenburg 2005; Von Blanckenburg et al. 2004). Cyr et al. (2010) found that ${ }^{10} \mathrm{Be}$-derived erosion rates increase linearly with increasing rock uplift rates. Some studies even derived uplift rates from observed denudation rates assuming that they are primarily controlled by rock uplift (Morell et al. 2015; Roux-Mallouf et al. 2015).

Despite the strong relationship between erosion rate and tectonic activity, a simpler way to make this connection is still missing since tectonic activity and uplift rates are difficult to measure. This study comprehensively compiles previously published erosion rate data derived by various methods, namely, ${ }^{10} \mathrm{Be}$ and sediment yield, and erosion rates calculated from suspended sediment load published by the United States Geological Survey (USGS) and correlates them to data related to tectonics, i.e., distance to tectonic plate boundary, peak ground acceleration, fault distribution, and slope.

\section{Methods/experimental}

This work uses several datasets. The largest dataset is the ${ }^{10} \mathrm{Be}$-derived erosion rate data compiled by Portenga and Bierman (2011) $(n=1555)$. We also added newer published ${ }^{10} \mathrm{Be}$-derived data $(n=546)$, erosion rates derived from sediment yield $(n=447)$, and erosion rates derived from other methods such as channel incision rates based on ${ }^{36} \mathrm{Cl}$ and ${ }^{14} \mathrm{C}(n=88)$. In addition, we downloaded suspended sediment loads from the USGS sediment data portal (U.S. Geological Survey) $(n=47)$. Only sites with at least 30 years of records were chosen. Of these, sites with no information about upstream drainage area or records for only several months of the year were discarded. Following previous studies (e.g., Cyr and Granger 2008; Olen et al. 2016), a rock density of $2.6 \mathrm{~g} \mathrm{~cm}^{-3}$ was used in order to estimate basin-wide erosion rates from the sediment yield data. Figure 1 shows the distribution of all data points used in this compilation.

It is important to note that the two main types of data used in this compilation, i.e., ${ }^{10} \mathrm{Be}$ - and sediment yield-derived erosion rates, are inherently different in that they represent different time scales. While sediment yields are measured over the past few decades, ${ }^{10} \mathrm{Be}$-derived data represent erosion rates from $10^{3}$ to $10^{6}$ years ago, both of which refer to shorter time scales than large-scale tectonic processes; therefore, they deal with generally unchanged tectonic settings.

Another important point is the skewed distribution of the data. Most of the data originate from the USA, the west of South America, central Europe, the Himalayas, and the Yangtze basin. These areas are studied more frequently than others due to many reasons, some being convenient and easily accessible and some are points of special interest, partly because they are located in tectonically active regions. Therefore, an effort was made to find data from less represented areas such as central Asia and Africa. Altogether, the area of the basins analyzed in this study represents about $10 \%$ of the Earth's land surface.

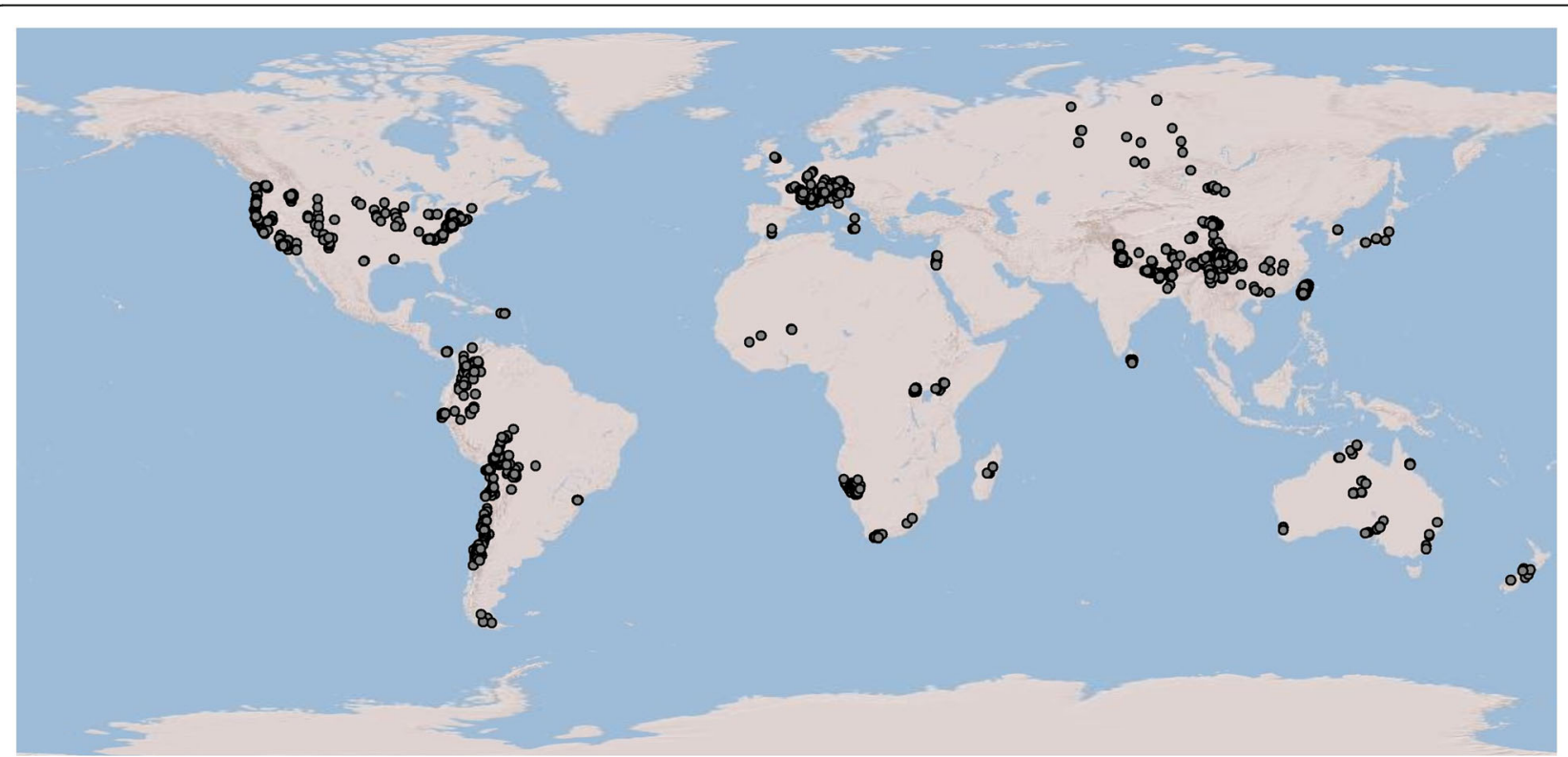

Fig. 1 Geographical distribution of data used for this study 
Basin boundaries were extracted using the basin tool of the hydrology toolset in ArcGIS. In most cases, the highresolution filled 1 arcsecond Advanced Spaceborne Thermal Emission and Reflection Radiometer (ASTER) Global Digital Elevation Model (GDEM) (U.S./Japan ASTER Science Team 2011) was used for the extraction, but the filled 3 arcsecond STRM DEM (Jarvis et al. 2008) was used for the larger basins. Since there are cases of multiple studies in the same area or data representing sub-basins, 211 selected basins were delineated with an area ranging from about $2.5 \times 10^{\circ}$ to $6.5 \times 10^{6} \mathrm{~km}^{2}$. For each basin, a basin-wide mean slope was calculated using the ArcGIS slope tool. Fault data derived from a map published by ESRI and attributed to the USGS (ESRI 2014) were used to calculate fault density for each basin. Additional data used in this study include tectonic plate boundary data published by Nordpil (2014) based on Bird (2003) and peak ground acceleration (PGA) data published by the Global Seismic Hazard Assessment Program (Giardini et al. 1999). This is a map produced by compiling regional maps representing the peak ground acceleration with a $10 \%$ chance of being exceeded within 50 years at a certain location due to earthquakes.

Using JMP pro 13.0, we examined the bilinear relationship of erosion rates with five tectonic-related factors. These include distance to fault, $P G A$, distance to tectonic plate boundaries, fault density, and mean basin-wide slope. From these, we chose those that correlated well to erosion rates and defined high and low value ranges for each as the upper and lower quartiles, respectively. Then, we grouped them in all possible combinations and calculated the mean erosion rate for each group.

\section{Results}

\section{Erosion rates in relation to tectonics}

Figure 2 and Table 1 show bivariate correlations of erosion rates with tectonic-related factors. The correlation between erosion rates and distance to tectonic plate boundary shows a statistically significant relationship.

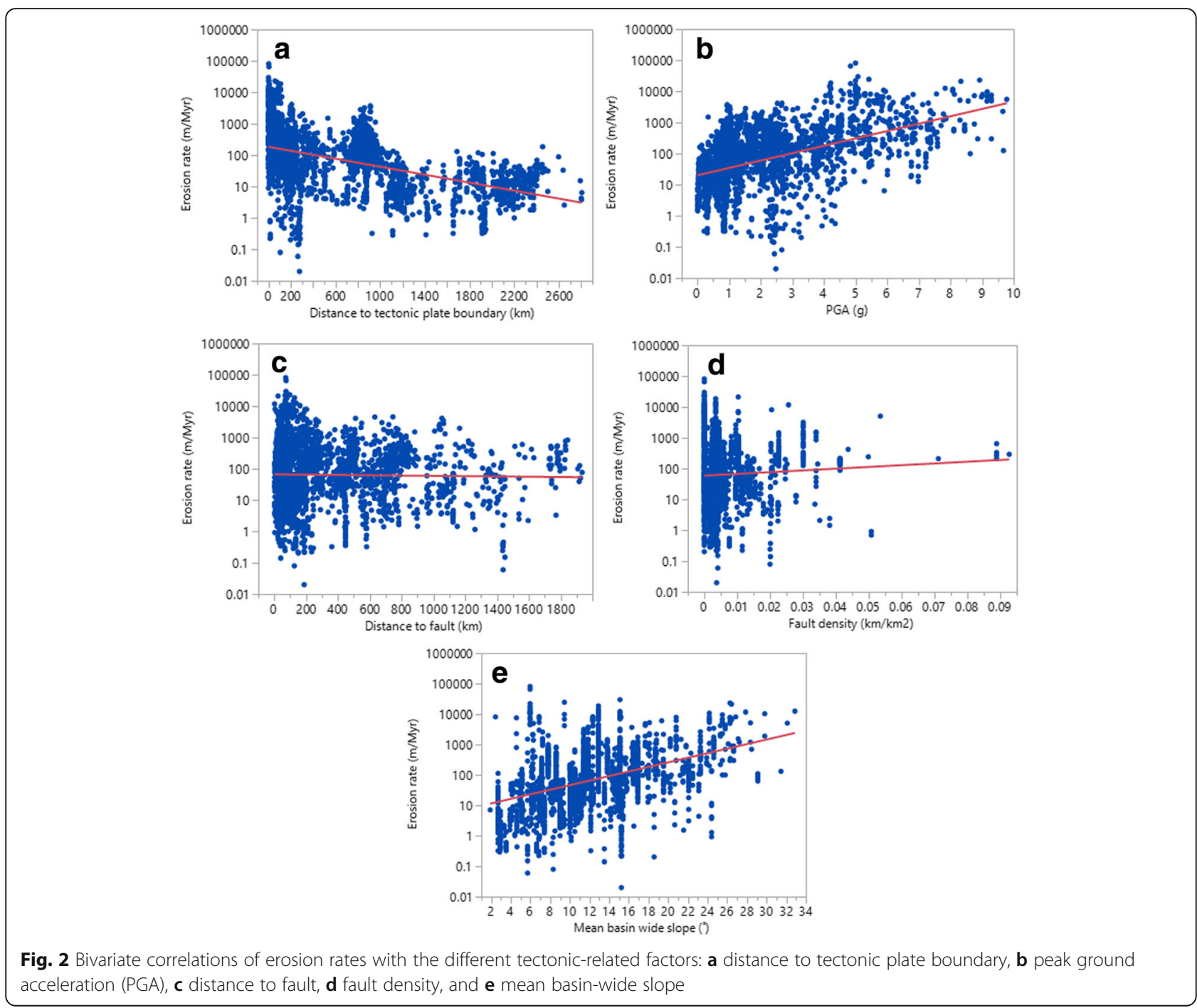


Table 1 Bivariate correlations of tectonic-related factors to erosion rate

\begin{tabular}{llllll}
\hline & Distance to the tectonic plate boundary $(\mathrm{km})$ & $P G A(\mathrm{~g})$ & Distance to the fault $(\mathrm{km})$ & Fault density $\left(\mathrm{km} / \mathrm{km}^{2}\right)$ & Mean basin-wide slope $\left(^{\circ}\right)$ \\
\hline$P^{*}$ & $<0.0001$ & $<0.0001$ & 0.3341 & 0.0127 & $<0.0001$ \\
$R^{* *}$ & -0.4861 & 0.4816 & -0.0173 & 0.0480 & 0.4093 \\
\hline
\end{tabular}

*P value

**Square root of $R$ squared, coefficient of determination

The correlation is negative, which means that the further away from tectonic plate boundaries, the slower the erosion rates. There is a statistically significant positive correlation between erosion rate and PGA. Higher PGA values correspond to higher erosion rates, and a similar $R$ value is obtained for the correlation between erosion rate and distance to boundary. The correlation between erosion rate and distance to fault is statistically insignificant. Although a slightly positive correlation with fault density is more significant, the $R$ value is very low. There is a statistically meaningful positive correlation between erosion rate and mean basin-wide slope.

\section{Grouping analysis}

Taking into account the poor correlations of fault distribution data with erosion rates, we did not use the distance to fault and fault density data in our discussion. The high, middle, and low values of the three remaining factors, i.e., distance to tectonic plate boundary, $P G A$, and mean basin-wide slope, were defined using the upper quartile, interquartile range, and lower quartile of data distribution: long, middle, and short distances from tectonic plate boundary ( $\mathrm{LD}, \mathrm{MD}$, and $\mathrm{SD}$ respectively); high, middle, and low PGA (HP, MP, and LP, respectively); and steep, middle, and gentle slopes (SS, MS, and GS, respectively) (Table 2). The complete dataset consists of 2683 data points with a mean erosion rate of $559.16 \mathrm{~m} / \mathrm{Myr}$. Out of the 27 possible combinations, four had no data points that met all the criteria and are empty groups. They are steep slope, high $P G A$, and long distance (SS HP LD); middle slope, high $P G A$, and long distance (MS HP LD); middle slope, low PGA, and short distance (MS LP SD); and gentle slope, high PGA, and long distance (GS HP LD). In addition, six other groups had 20 data points or less, which are not included for further analysis.

Table 3 shows the mean erosion rates of the remaining 17 groups, arranged from low to high mean erosion rates. The groups with the highest mean erosion rates ranging from 1085.27 to $11,642.11 \mathrm{~m} / \mathrm{Myr}$ are middle slope, high $P G A$, and short distance (MS HP SD); steep slope, high $P G A$, and short distance (SS HP SD); and gentle slope, high $P G A$, and short distance (GS HP SD). The groups with the lowest erosion rates ranging from 10.13 to $18 \mathrm{~m} / \mathrm{Myr}$ are gentle slope, middle $P G A$, and long distance (GS MP LD); middle slope, low PGA, and long distance (MS LP LD); and gentle slope, low PGA, and long distance (GS LP LD. The group with the largest number of data points has a mean erosion rate of $267.22 \mathrm{~m} / \mathrm{Myr}$ and is middle slope, middle $P G A$, and middle distance (MS MP MD).

\section{Discussion}

The mean erosion rate for this study (about $559 \mathrm{~m} / \mathrm{Myr}$, Table 3) is significantly higher than the previously reported rate by Portenga and Bierman (2011): a mean of $218 \mathrm{~m} / \mathrm{Myr}$ for basins and $12 \mathrm{~m} / \mathrm{Myr}$ for outcrops. There is one major difference between this study and that of Portenga and Bierman (2011). The latter used a compilation of ${ }^{10} \mathrm{Be}$-derived data only, but this study compiled different types of data including sediment yield. Erosion rates from sediment yield are those for recent years when human activity is considered to accelerate erosion rates (e.g., Saunders and Young 1983; Von Blanckenburg 2005; Walling and Webb 1996) and could account for the overall higher mean erosion rate.

\section{Interpretation of bivariate correlation}

The correlation of erosion rates to distance to tectonic plate boundary is negative (Fig. 2a), suggesting that enhanced tectonic activity along the contact lines of the plates is favorable for erosion. $P G A$ is an expression of probable ground acceleration due to earthquakes; thus, it is a direct indicator of tectonic activity. Figure $2 \mathrm{~b}$ shows that higher erosion rates tend to occur at locations with higher $P G A$ values. The strongest correlation of erosion rates is that with distance to tectonic plate boundary, although its $R$ value is similar to that of $P G A$ (Table 1). This emphasizes the strength of the former as a simple geographical predictor of erosion rates.

Table 2 High, middle, and low range values for each parameter defined using quartiles

\begin{tabular}{|c|c|c|c|c|c|c|}
\hline \multirow[b]{2}{*}{ Upper quartile } & \multicolumn{2}{|c|}{ Distance to tectonic the plate boundary $(\mathrm{km})$} & \multicolumn{2}{|c|}{$P G A(g)$} & \multicolumn{2}{|c|}{ Mean basin-wide slope $\left(^{\circ}\right)$} \\
\hline & LD & $>1118.69$ & HP & $>2.86$ & SS & $>15.03$ \\
\hline Interquartile range & MD & $94.34-1118.69$ & MP & $0.68-2.86$ & MS & $8.1-15.03$ \\
\hline Lower quartile & SD & $<94.34$ & LP & $<0.68$ & GS & $<8.1$ \\
\hline
\end{tabular}


Table 3 Mean erosion rate (m/Myr) and its standard deviation (SD), median, minimum, and maximum for each of the groups that contain more than 20 data points as well as the complete data set

\begin{tabular}{lllllll}
\hline & $n$ & Mean & SD & Median & Minimum & Maximum \\
\hline All data & 2683 & 559.16 & 2656.37 & 65.7 & 0 & 80,700 \\
GS MP LD & 130 & 10.13 & 15.27 & 3.04 & 0.29 & 113.25 \\
MS LP LD & 292 & 16.27 & 15.14 & 11.6 & 1 & 115.68 \\
GS LP LD & 154 & 18 & 25.06 & 9.93 & 0.88 & 186.48 \\
MS MP LD & 72 & 26.34 & 11.3 & 25.01 & 4.85 & 57.2 \\
GS LP MD & 97 & 65.2 & 173.36 & 11.73 & 0.28 & 1513.6 \\
MS LP MD & 61 & 70.53 & 58.76 & 47.81 & 0.32 & 223 \\
SS LP MD & 36 & 71.39 & 50 & 55.1 & 14.6 & 233.6 \\
GS MP MD & 165 & 183.86 & 295.73 & 74.61 & 0.06 & 2190 \\
SS HP MD & 100 & 193.96 & 286.49 & 93.38 & 0.2 & 1773.83 \\
MS MP SD & 133 & 215.18 & 433.57 & 43 & 0.24 & 4131 \\
MS MP MD & 468 & 267.22 & 516.68 & 98.33 & 0.08 & 4151.28 \\
GS MP SD & 66 & 333.88 & 403.15 & 180.97 & 0.22 & 1987.16 \\
SS MP MD & 306 & 357.01 & 456.15 & 174.345 & 0.02 & 3236.7 \\
MS HP MD & 95 & 829.49 & 2740.38 & 118.49 & 0.56 & 18,400 \\
MS HP SD & 248 & 1085.27 & 2360.73 & 357.7 & 15.43 & 24,300 \\
SS HP SD & 178 & 2553.63 & 4131.26 & 800 & 0 & 29,500 \\
GS HP SD & 28 & $11,642.11$ & $18,242.28$ & 7000 & 80 & 80,700 \\
\hline
\end{tabular}

As noted, the erosion rate data we used show a slightly positive correlation to distance to fault and a slightly negative correlation to fault density (Fig. 2c, d), but they are statistically insignificant. This may be because faults have quite different levels of activity even locally, and hence, each fault does not represent regional tectonics well, in contrast to each plate boundary. On a local scale, a connection between erosion rates and faults has been shown in the past, for example, erosion has been shown to influence seismicity along faults (Steer et al. 2014). If enough data are collected from a single basin, a correlation could be found between erosion rate and fault distribution. In addition, more information regarding the activity level of the faults might also improve the correlation. However, the global fault data used here are not comprehensive and tectonic activity on a larger scale related to plate boundaries correlates better to erosion rates.

\section{Implication of group analysis}

Groups with the combinations of high $P G A$ and long distance and low $P G A$ and short distance are either empty or include very few data points. Groups with a relatively large number of data points are generally those with the combination of low PGA and long distance, high $P G A$ and short distance, and middle $P G A$ and middle distance (Table 3). This confirms that $P G A$, and therefore tectonic activity, is directly affected by distance to tectonic plate boundary and is also apparent in the distribution of $P G A$ as a function of distance to plate (Fig. 3).

Table 3 has implications on the effect of each parameter on erosion rates. The seven groups with the lowest erosion rates all include long distance (LD) and/or low PGA (LP), whereas the other 10 groups with highest erosion rates did not include any of these. In addition, the top part of Table 3 with low erosion rates is dominated by groups including long distance (LD), while the bottom part of the table with high erosion rates is dominated by groups including short distance (SD). A similar trend is observed for groups with the correlation of low $P G A$ with low erosion rates and high $P G A$ with high erosion rates but to a smaller effect. No such trend exists for groups with gentle and steep slopes. This points out that distance to tectonic plate boundary is the most important factor and emphasizes its strong effect on erosion rates. Although there is no apparent correlation between slope and erosion rates, numerous studies have shown that a steeper terrain is more erodible than a gentler terrain, which is naturally acceptable in relation to change in slope stability. Indeed, the data we used show a significant relationship between erosion rate and slope when examining a bivariate correlation of all the data, even though they are scattered. However, when the data are separated into groups with different characteristics and sections of the data are separately examined, this relationship becomes less apparent. It is important to note that the slope parameter used in this study is the mean basin-wide slope, and its lumped characteristics do not reflect the actual complex distribution of slope within a basin. To address this problem, we take a closer look at the group with the highest mean erosion rate, i.e., GS HP SD, which has a mean erosion rate of $11,642.11 \mathrm{~m} / \mathrm{Myr}$ that is an order of magnitude higher than the next group (SS HP SD, $2553.63 \mathrm{~m} / \mathrm{Myr}$ ). In this

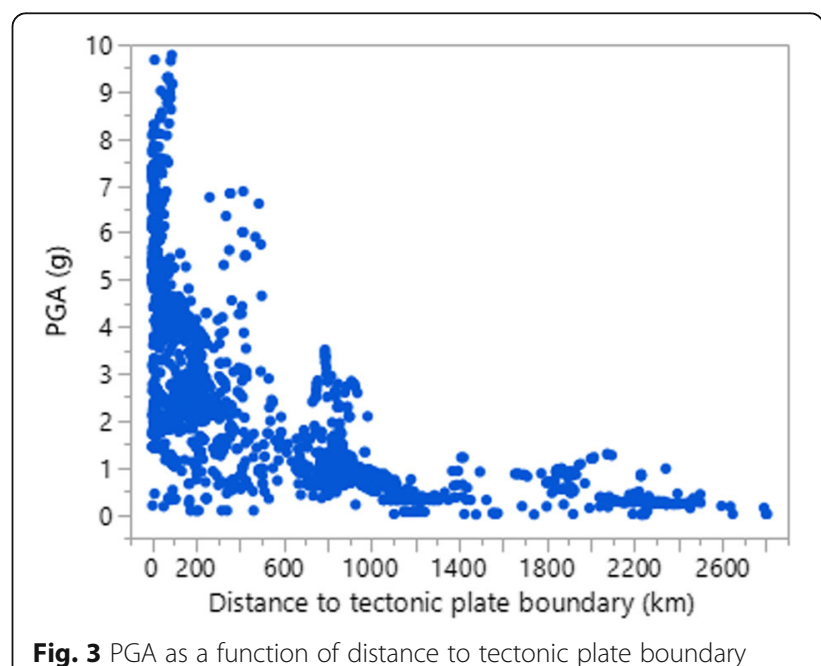


group, all but two data points are located on the southwestern side of Taiwan. Taiwan is known for its exceptionally high erosion rates due to a combination of extremely wet climate and a tectonically active environment (Chen-Feng et al. 1988; Dadson et al. 2003). Taiwan's topography consists of roughly north-south orienting mountain belts with peaks of almost $4000 \mathrm{~m}$ in elevation. This means that even though the mean basinwide slope of the southwest basins is lower due to the gentle slopes of the lower extensive depositional plains, the rivers originate higher up in the mountain range where slopes are steeper and are able to produce abundant sediment. A distribution map of all data points from Taiwan shows that the majority of the points belong to the SS HP SD group, which is theoretically the group with the highest expected erosion rates as it represents steep slopes and active tectonics. The other points mainly belong to the gentle slope and active tectonic group (GS HP SD) (Fig. 4). The two data points of the GS HP SD group from areas other than Taiwan are located on a tributary of the Orinoco basin in Colombia basin and in the upstream part of a tributary of the Indus River. These cases also have steeper slopes in the upstream areas, but the overall basin slope is low due to wide depositional areas. The same applies to the case of the next group in line, i.e., middle slope and active tectonics (MS HP SD). Here, most data points are from the Himalayan origins of the Ganges River, the Andean origins of the Magdalena River in Colombia, the San Gabriel mountain and the San Bernardino mountains

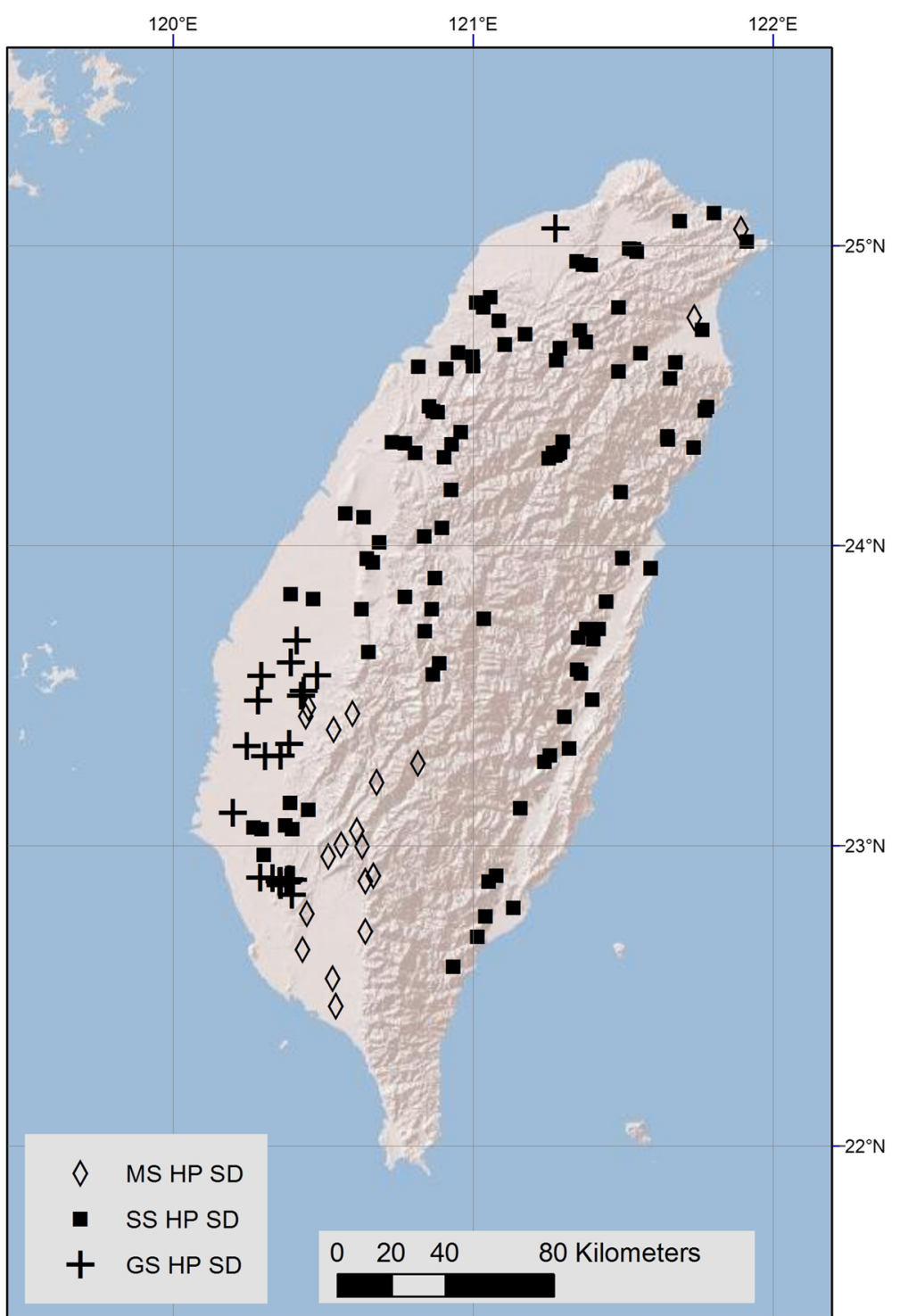

Fig. 4 Distribution of data points in Taiwan: SS HP SD (squares), GS HP SD (crosses), and MS HP SD (diamonds) 
along the San Andreas Fault, and the southwest part of Taiwan. As indicated, steep slopes in these areas are not properly represented when referring to mean basin-wide slope because broad depositional areas are included. It is quite common that steep mountainous river basins with high erosion rates produce broad depositional landforms such as alluvial fans in piedmont areas. Therefore, while a dissonance between existing steep slopes in a basin and its significantly lower mean basin-wide slope can be smoothed when examining large data, this is more problematic when looking at smaller data sets and superficial correlations of lower mean basin slope with high erosion rates can occur. This should be taken into account in future erosion rate studies.

It is expected that the group with the lowest erosion rates would be that of gentle slope, low $P G A$, and long distance (GS LP LD). Results show that this group indeed has a low mean erosion rate, but it is not the lowest. The MS LP LD group has a very similar mean erosion rate and is also dominated by a tectonically inactive setting (low PGA and long distance), and the GS MP LD group has the lowest mean erosion rate even though it is from middle $P G A$ areas. This group is dominated by data originating from the middle and southern parts of Australia, where basins have a low mean annual precipitation ranging from about 200 to $425 \mathrm{~mm} /$ year. Here, the dry climate might contribute to the slow erosion rates.

\section{Effect of tectonic activity on erosion rates}

The results of this study indicate that erosion rates are strongly related to tectonic activity. A simple direct explanation would be that tectonic activity with ground motion weakens and fractures bedrock, creates debris, and hence incites physical erosion (Molnar et al. 2007). In addition, influences of erosion on tectonics may cause their correlation. Whipple (2009) has shown that erosion in active mountain belts tends to influence tectonic processes by thinning the crust, which accelerates uplift through isostasy. This process would be further accelerated with the help of increased precipitation on mountain slopes due to the orographic effect (Barros and Lettenmaier 1994). Furthermore, tectonic activity produces high relief topography prone to erosion, resulting in higher erosion rates. The effects of slope and relief on erosion rates have been discussed extensively (e.g., Ahnert 1970; Portenga and Bierman 2011; Summerfield and Hulton 1994). This study also shows that higher erosion rates generally occur in basins with steeper slopes (Fig. 2e), and basins closer to tectonic plate boundaries and/or with higher $P G A$ values have higher mean slopes (Fig. 5). This means that stronger tectonic activities increase slope steepness and thus increase slope instability and erosion rates.

This study utilized data from more than 2600 points and concluded that erosion rates are strongly dependent on tectonic activity. However, many of the data are from tectonically active areas, so lower erosion rates in areas of weak tectonics need to be confirmed using more data from such areas.

\section{Conclusions}

Understanding erosion rate distribution and its controlling factors is necessary for discussing and predicting landscape formations. Global-scale studies provide general ideas about these processes. As part of these efforts, this study has utilized global DEM data and an extensive compilation of erosion rates derived from various methods. The results of this research show that erosion rates are strongly related to tectonic activity. A strong coupling between $P G A$, which is a direct indicator of tectonic activity, and distance to tectonic plate boundary suggests that the latter can also be an indicator of tectonic activity. This means that the easy-to-measure parameter of distance to plate boundary can be used to make general correlations between erosion rates and tectonic activity on a global scale, despite the compilations in accurately measuring tectonic activity. The power of this parameter is further emphasized through the group analysis where the strongest correlation is between high
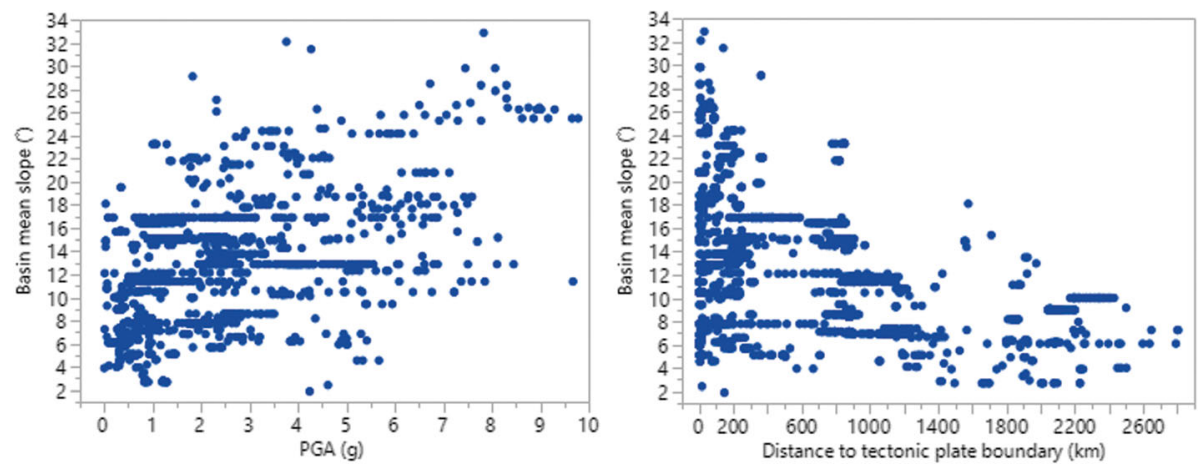

Fig. 5 Mean basin slope as a function of PGA and distance to tectonic plate boundary 
and low erosion rates and short and long distances to tectonic boundaries, respectively, and not between erosion rates and PGA or mean basin-wide slope, even though the latter is well known as a parameter that affects erosion rates. The precise way in which tectonic activity is connected to erosion rates is yet unknown; however, some possibilities include influence through seismic shattering and fracturing of rocks, a relation between erosion and isostatic uplift, which is increased by orographic rainfall on uplifted mountains, and increased slope steepness and instability in such mountains. These are supported by the strong connections among high $P G A$, proximity to tectonic boundaries, and steep slopes. Similar to some previous studies, our study has found that on a global scale, a significant bivariate correlation between erosion rates and mean basin-wide slope exists. However, this relationship is not reflected when smaller data sets in the group analysis are taken into account; therefore, this parameter should be used with caution and careful consideration since it cannot account for the complex distribution of slopes within a basin. Although this study also discusses some regional issues, such as some unique drainage basins in Taiwan, analyses are essentially global and deal with only general trends. Further research is needed to understand more detailed mechanisms that determine regional and local erosion rates.

\section{Abbreviations}

ASTER: Advanced Spaceborne Thermal Emission and Reflection Radiometer; GS: Gentle slope; HP: High PGA; LD: Long distance; LP: Low PGA; MD: Middle distance; MP: Middle PGA; MS: Middle slope; PGA: Peak ground acceleration; SD: Short distance; SS: Steep slope; USGS: United States Geological Survey

\section{Acknowledgements}

We thank the editor and two anonymous reviewers for their helpful comments that improved the manuscript.

\section{Funding}

This work was supported by JSPS KAKENHI Grant Numbers JP15K12452 and JP15H01782.

\section{Authors' contributions}

Both authors read and approved the final manuscript.

\section{Competing interests}

The authors declare that they have no competing interests.

\section{Publisher's Note}

Springer Nature remains neutral with regard to jurisdictional claims in published maps and institutional affiliations.

\section{Author details}

'Department of Natural Environmental Studies, The University of Tokyo, 5-1-5 Kashiwanoha, Kashiwa City, Chiba 277-8563, Japan. ${ }^{2}$ Center for Spatial Information Science, The University of Tokyo, 5-1-5 Kashiwanoha, Kashiwa City, Chiba 277-8568, Japan.
Received: 17 August 2017 Accepted: 2 December 2017

Published online: 19 December 2017

\section{References}

Ahnert F (1970) Functional relationships between denudation, relief, and uplift in large, mid-latitude drainage basins. Am J Sci 268:243-263

Barros AP, Lettenmaier DP (1994) Dynamic modeling of orographically induced precipitation. Rev Geophys 32:265-284

Bird P (2003) An updated digital model of plate boundaries. Geochem Geophy Geosy:4. https://doi.org/10.1029/2001GC000252

Chen-Feng Y, Typhoon L, Brown L, Shen JJ, Ju-Chin C (1988) ${ }^{10}$ Be study of rapid erosion in Taiwan. Geochim Cosmochim Acta 52:2687-2691

Cyr AJ, Granger DE (2008) Dynamic equilibrium among erosion, river incision, and coastal uplift in the northern and central Apennines, Italy. Geology 36:103-106

Cyr AJ, Granger DE, Olivetti V, Molin P (2010) Quantifying rock uplift rates using channel steepness and cosmogenic nuclide-determined erosion rates: examples from northern and southern Italy. Lithosphere 2:188-198

Dadson SJ, Hovius N, Chen H, Dade WB (2003) Links between erosion, runoff variability and seismicity in the Taiwan orogen. Nature 426(6967):648-651

ESRI. (2014) Global Faults layer from ArcAtlas. http://www.arcgis.com/home/item. html?id=a5496011 fa494b99810e4deb5c618ae2\#overview. Accessed August 2016

Galy A, France-Lanord C (2001) Higher erosion rates in the Himalaya: geochemical constraints on riverine fluxes. Geology 29:23-26

Giardini D, Grünthal G, Shedlock KM, Zhang P (1999) The GSHAP global seismic hazard map. Ann Geophys 42:1225-1230

Griffiths GA (1979) High sediment yields from major rivers of the Western Southern Alps, New Zealand. Nature 282:61-63

Griffiths GA (1981) Some suspended sediment yields from South Island catchments, New Zealand. J Am Water Resour As 17:662-671

Hovius N, Stark CP, Allen PA (1997) Sediment flux from a mountain belt derived by landslide mapping. Geology 25:231-234

Jarvis A, Reuter HI, Nelson A, Guevara E (2008) Hole-filled SRTM for the globe version 4. Available from the CGIAR-CSI SRTM 90m database (http://srtm.csi. cgiar.org)

Kump LR, Brantley SL, Arthur MA (2000) Chemical weathering, atmospheric $\mathrm{CO}_{2}$, and climate. Annu Rev Earth Planet Sci 28:611-667

Matsushi Y, Wakasa S, Matsuzaki H, Matsukura Y (2006) Long-term denudation rates of actively uplifting hillcrests in the Boso Peninsula, Japan, estimated from depth profiling of in situ-produced cosmogenic ${ }^{10} \mathrm{Be}$ and ${ }^{26} \mathrm{Al}$. Geomorphology 82:283-294

Milliman JD, Syvitski JP (1992) Geomorphic/tectonic control of sediment discharge to the ocean: the importance of small mountainous rivers. J Geol 100:525-544

Molnar P, Anderson RS, Anderson SP (2007) Tectonics, fracturing of rock, and erosion. J Geophys Res Earth 112

Morell KD, Sandiford M, Rajendran C, Rajendran K, Alimanovic A, Fink D, Sanwal J (2015) Geomorphology reveals active décollement geometry in the central Himalayan seismic gap. Lithosphere 7:247-256

Nordpil (2014) Tectonic plate GIS data. https://nordpil.com/resources/tectonicplates-gis-data/. Accessed Sept 2016

Olen SM, Bodo B, Strecker MR (2016) Role of climate and vegetation density in modulating denudation rates in the Himalaya. Earth Planet Sc Lett 445:57-67

Portenga EW, Bierman PR (2011) Understanding Earth's eroding surface with ${ }^{10} \mathrm{Be}$ GSA Today 21:4-10

Roux-Mallouf L, Godard V, Cattin R, Ferry M, Gyeltshen J, Ritz JF, Drupka D, Guillou V, Arnold M, Aumaître G (2015) Evidence for a wide and gently dipping Main Himalayan Thrust in western Bhutan. Geophys Res Lett 42: 3257-3265

Saunders I, Young A (1983) Rates of surface processes on slopes, slope retreat and denudation. Earth Surf Proc Land 8:473-501

Scharf TE, Codilean AT, De Wit M, Jansen JD, Kubik PW (2013) Strong rocks sustain ancient postorogenic topography in southern Africa. Geology 41:331-334

Steer P, Simoes M, Cattin R, Shyu JB (2014) Erosion influences the seismicity of active thrust faults. Nat Commun 5:5564

Summerfield M, Hulton N (1994) Natural controls of fluvial denudation rates in major world drainage basins. J Geophys Res Solid Earth 99:13871-13883

USGS Sediment Data Portal. https://cida.usgs.gov/sediment/\#. Accessed September 2015

U.S./Japan ASTER Science Team (2011) ASTER Global Digital Elevation Mode V002. https://asterweb.jpl.nasa.gov/gdem.asp. Accessed August 2014 
Von Blanckenburg F (2005) The control mechanisms of erosion and weathering at basin scale from cosmogenic. nuclides in river sediment. Earth Planet Sc Lett 237:462-479.

Von Blanckenburg F, Hewawasam T, Kubik PW (2004) Cosmogenic nuclide evidence for low weathering and denudation in the wet, tropical highlands of Sri Lanka. J Geophys Res-Earth 109, https://doi.org/10.1029/2003JF000049.

Walling DE, Webb B, (1996) Erosion and sediment yield: global and regional perspectives. Proceedings of an international symposium held at Exeter, UK, July 1996. IAHS

Whipple KX (2009) The influence of climate on the tectonic evolution of mountain belts. Nat Geosci 2:97-104

\section{Submit your manuscript to a SpringerOpen ${ }^{\bullet}$ journal and benefit from:}

- Convenient online submission

Rigorous peer review

- Open access: articles freely available online

- High visibility within the field

- Retaining the copyright to your article

Submit your next manuscript at $\gg$ springeropen.com 